\title{
Fractional Flow Reserve (FFR) guided Percutaneous Coronary Intervention (PCl) to Avoid Inappropriate Stenting in Patient with Angiographically Significant Stenotic Coronary Artery Lesion-Our Experiences at Apollo Hospitals Dhaka
}

AHM Waliul Islam¹, Shams Munwar ², Azfar Hossain ${ }^{3}$, AQM Reza ${ }^{2}$, Sahabuddin Talukder 2, Tamzeed Ahmed ${ }^{2}$, Kazi Atiqur Rahman 4

\begin{abstract}
:
Background: Importance of Physiological study by Fractional Flow Reserve (FFR) in the management of patient with coronary artery disease (CAD is well established.

Objective: Angiographic-guided percutaneous coronary intervention $(\mathrm{PCl})$ is a common practice in Bangladeshi interventional era. Data on Pre-PCI physiological study by Fractional Flow Reserve (FFR) in our patient is not available. Therefore, our primary aim was to perform pre-PCI FFR to assess the angiographically significant coronary stenosis and thus to avoid inappropriate stenting.

Methods: Total 22 patients (Male 20, Female 2) were enrolled in this observational non-randomized prospective cohort. Patient who had angiographically significant lesion, planned for physiological study by pre-PCI FFR. Cut off value for FFR were clinically
\end{abstract}

significant only if $\mathrm{Pd} / \mathrm{Pa}$ ratio $<0.75$ and differed stenting if $>\mathbf{0 . 7 6 - 0 . 8 0}$ or above.

Results: In the studied patient population, FFR done in total 27 vessels of 22 patients. Among the vessel wise FFR distribution were in LAD 67\%(18), LCX 14.8\%(4), RCA $14.8 \%(4)$ and Ramus Intermedius $3.7 \%$ (1). FFR was nonsignificant $(<0.75)$ in $59 \%$ (13) patients and significant $(>0.75)$ were in $41 \%(9)$ patients.

Conclusion: In this single center, very preliminary observational prospective cohort of non-randomized study, we found, that FFR is an important aid to perform PCl in patient with angiographically significant coronary lesion, and to avoid inappropriate stenting of insignificant stenosis by physiological study. Thus, to reduce cost and untoward effects of inappropriate stenting.

Key words: PCI, FFR

(Bangladesh Heart Journal 2019; 34(1): 37-43)

Introduction;

Myocardial ischemia is a predictor for clinical outcomes in patient with CAD. The presence of myocardial ischemia symptoms is an important determinant or risk factors for adverse clinical outcome. ${ }^{1}$ Angiography is the established invasive approach for assessing coronary artery disease, but its ability to evaluate the functional significance of

1. Consultant, Interventional Cardiology, Apollo Hospitals Dhaka, Bangladesh.

2. Sr. Consultant- Interventional Cardiology, Apollo Hospitals Dhaka, Bangladesh.

3. Specialist, Interventional Cardiology, Apollo Hospitals Dhaka, Bangladesh.

4. Consultant, Interventional Cardiology, Apollo Hospitals Dhaka, Bangladesh.

Department of Interventional Cardiology, Apollo Hospitals Dhaka

Address of Correspondence: Prof. Dr. AHM Waliul Islam, Consultant Interventional Cardiology, Apollo Hospitals Dhaka, Bangladesh. Mobile: +8801713228884, E-mail: drwali62@gmail.com

DOI: https://doi.org/10.3329/bhj.v34i1.41906

Copyright ( $\subseteq 2017$ Bangladesh Cardiac Society. Published by Bangladesh Cardiac Society. This is an Open Access articles published under the Creative Commons Attribution-NonCommercial 4.0 International License (CC BY-NC). This license permits use, distribution and reproduction in any medium, provided the original work is properly cited and is not used for commercial purposes. 
stenosis is limited and lesion can be underestimated or overestimated. This can lead the patient having $\mathrm{PCl}$ that is unnecessary. Currently, the hemodynamic significance of a coronary lesion includes noninvasive functional testing like stress echocardiography or stress perfusion scan and invasive testing, fractional flow reserve (FFR) and IFR. Percutaneous coronary intervention $(\mathrm{PCl})$ is an established mode of treatment modality to open angiographically significant coronary stenosis. Revascularization of stenotic coronary artery lesion which induce ischemia can improve patient's symptoms and outcomes. $^{2-3}$

Fractional Flow Reserve (FFR) is generally known as index to assess the physiological significance of coronary stenosis and defined as the ratio of the distal coronary pressure to the proximal pressure during maximum hyperemia using a pressure wire during maximal vasodilatations by using intracoronary or IV adenosine. ${ }^{4}$ It has been shown to be an effective method for guiding revascularization. ${ }^{5-7} \quad$ FFR value of $<0.75$ identifies ischemia-causing coronary stenosis with an accuracy of more than $90 \% .^{8}$ FFR's clinical effectiveness first demonstrated by FAME trial $^{5}$ which compared angiography guided $\mathrm{PCl}$ with $\mathrm{FFR}$ guided $\mathrm{PCl}$ in patients with Multivessel diseases has showed favorable outcome in FFR-guided PCl.

Recent Guideline on myocardial revascularization recommend revascularization for ischemia related stenosis and medical therapy for non-ischemia stenosis. ${ }^{9}$ Current guideline recommendation for FFR guided PCl is class $1 \mathrm{~A}$ for $\mathrm{ESC}$ and class IIA from American College of Cardiology.

In our hospital patient population, data on FFR guided $\mathrm{PCl}$ were not available. Therefore, we carried out this very preliminary observational cohort study to see the clinical significance of FFR guided $\mathrm{PCl}$ in patients with angiographically significant lesion, thus to avoid inappropriate stenting and cost to patients.

\section{Methods and materials:}

Total 22 patients (Male 20, Female 2), were enrolled in this non randomized prospective cohort study of patients. Who had CAG done at our center and found to have approximately $>70-80 \%$ lesion were planned for pre- $\mathrm{PCl}$ FFR study. Subsequent PCI based on FFR study. Study period were November 2017 to December 2018. Patients were only selected as cases when they were still on aspirin and clopidogrel. Patient were routinely loaded with pre-procedural Ticagrelor $180 \mathrm{mg}$ or Clopidogrel $300 \mathrm{mg}$ and Aspirin $300 \mathrm{mg}$ with post procedural maintenance doses Ticagrelor $180 \mathrm{mg}$ bid Clopidogrel $150 \mathrm{mg}$ and Aspirin 150mg. Common exclusion criteria were ST elevated acute MI, NSTEMI, Heart Failure, referral for CABG.

\section{Coronary angiogram:}

Diagnostic CAG were performed using 5-6 French Terumo Radial catheter through radial approaches. To avoid spasm and to achieve maximal epicardial vasodilatation, intracoronary $(0.1-0.3 \mathrm{mg})$ nitroglycerine and mild sedation with $1 \mathrm{mg}$ IV midazolam was commonly given to enrolled patient with prior written consent for the procedures in detail. All stenosis was assessed visually. Patient with approximately $>70 \%-80 \%$ lesion were enrolled for pre-PCI FFR study.

\section{FFR:}

FFR was defined as the ratio between mean distal coronary pressure and mean aortic pressure at maximal hyperemia. Intracoronary pressure wire 0.014 -inch was introduced via a $6 \mathrm{~F}$ guiding catheter, calibrated, advanced into the coronary artery and placed $>3 \mathrm{~cm}$ distal to the assessed stenosis as described previously. ${ }^{4}$ FFR was assessed after the administration of $200 \mathrm{mcgm}$ adenosine to achieve maximal hyperemia. FFR was calculated as the ratio of the mean distal (trans-stenotic) coronary pressure measure by the pressure wire to the aortic pressure measured by the guiding catheter at maximal hyperemia. Generally, $\mathrm{PCl}$ was performed in patients with FFR $<0.75$ and deferred in those with FFR $>0.80$. For FFR value between $>0.75$ to $<0.80$, kept on medical management.

\section{Results:}

Figure 1. shows the distribution of patient. Total 22 patients (Male 20, Female 2) were enrolled in this observational non-randomized prospective cohort. Patient who had angiographically significant lesion, planned for pre- $\mathrm{PCl}$ physiological study by FFR. Cut off value for FFR were clinically significant only if $\mathrm{Pd} / \mathrm{Pa}$ ratio $<0.75$ and deferred stenting if $>0.76$. Fig 2. Shows the distribution of CAD risk factors. Fig 3 . Shows the percentage distribution of coronaries in which FFR was done. Among the vessel wise FFR distribution; in LAD 67\%(18), LCX 14.8\%(4), RCA $14.8 \%(4)$ and Ramus Intermedius 3.7\%(1). Fig 4. Shows the percentage distribution Significant FFR and non-significant FFR. Non-significant were found in $59 \%(13)$ patient and significant i.e., $>0.75$ were in $41 \%(9)$ patient. $<P I$ add figure 1-4 here $>$

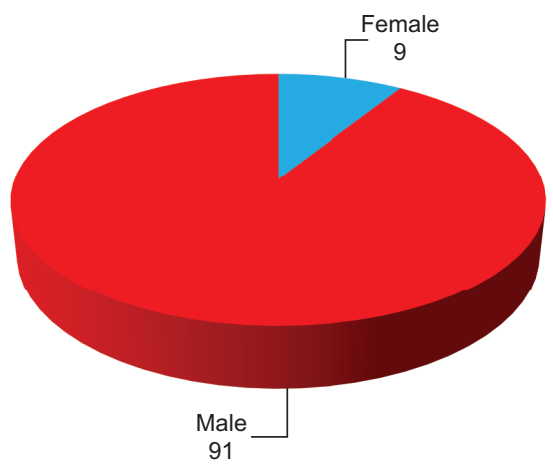

Fig.-1: Shows the distribution of Male and Female in the studied group 


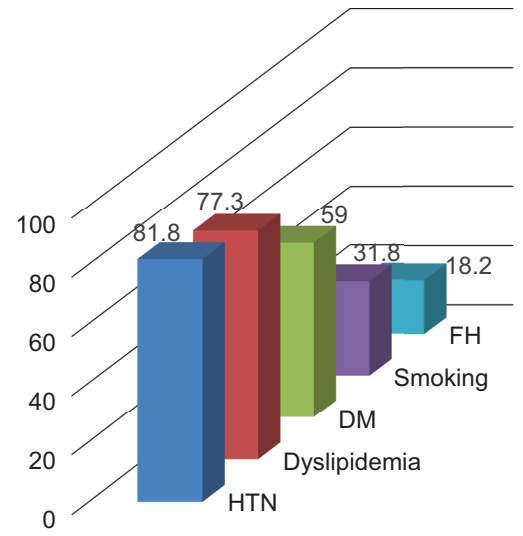

Fig.-2: Percentage Distribution of CAD risk factors

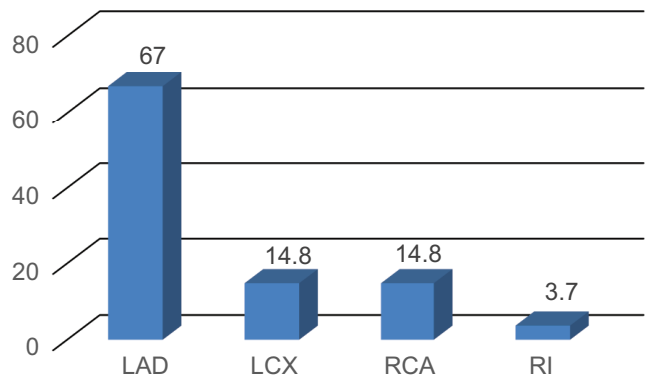

Fig.-3: Percentage distribution of studied coronary artery

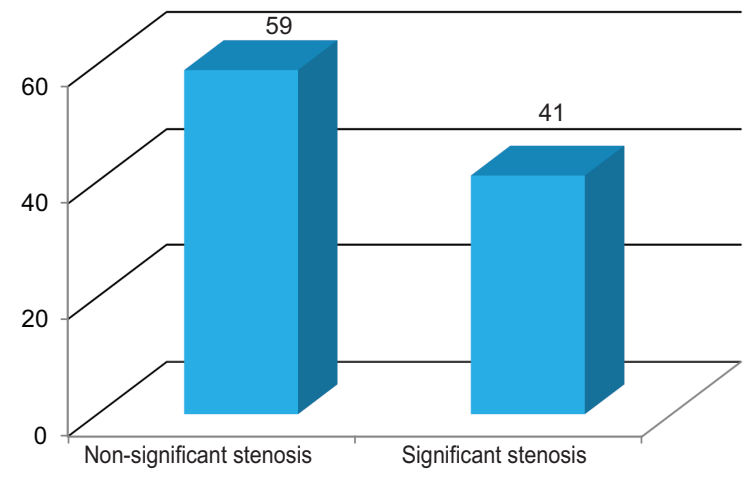

Fig.-4: Percentage distribution of Significant and non-significant Coronary lesion by FFR guided physiological study

Fig 5. Coronary Angiogram and FFR in a patient with angiographically significant Proximal OM lesion on left panel and physiological study by FFR of 0.95 , insignificant and left for medical management. Fig 6. Coronary Angiogram and FFR in a patient with angiographically significant Proximal LAD lesion on left panel and physiological study by FFR of 0.75 borderline and kept on medical management. Fig 7. Coronary Angiogram and FFR in a patient with angiographically significant Proximal LAD lesion on left panel and physiological study by FFR of 0.81 and kept on medical management. Fig 8. Coronary Angiogram and FFR in a patient with angiographically significant Proximal LAD lesion on left panel and physiological study by FFR of $<0.72$ and stenting was done. $<\mathrm{pl}$ add figure 5-8 here $>$
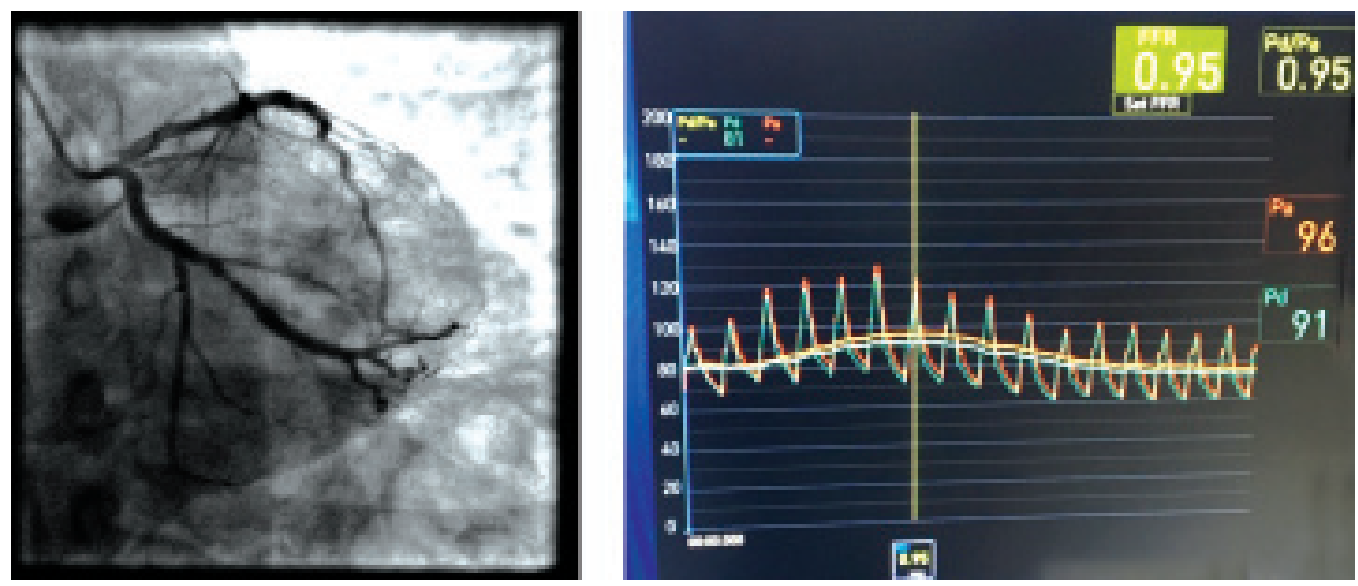

Fig.-5: Coronary Angiogram and FFR in a patient with angiographically significant Proximal OM lesion on left panel and physiological study by FFR of 0.95, insignificant and left for medical management 

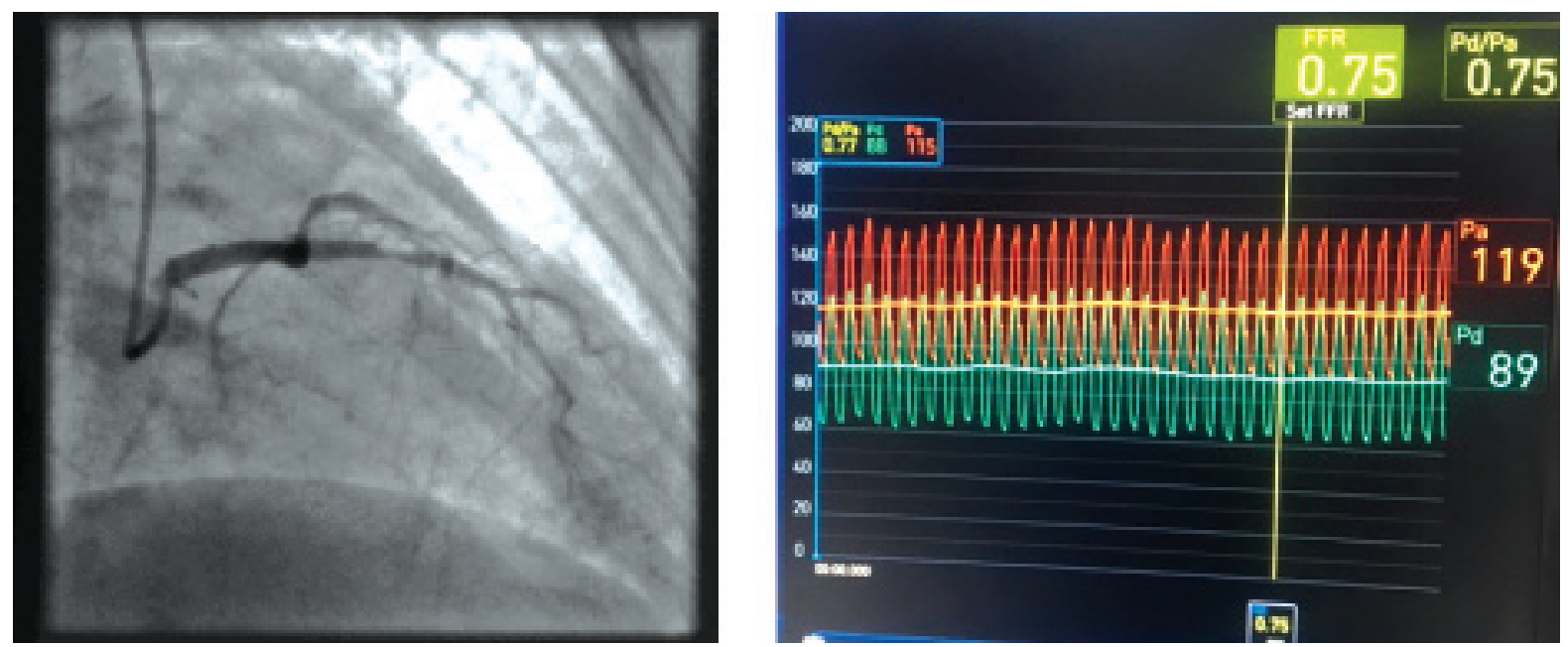

Fig.-6: Coronary Angiogram and FFR in a patient with angiographically significant Proximal LAD lesion on left panel and physiological study by FFR of 0.75 borderline and kept on medical management
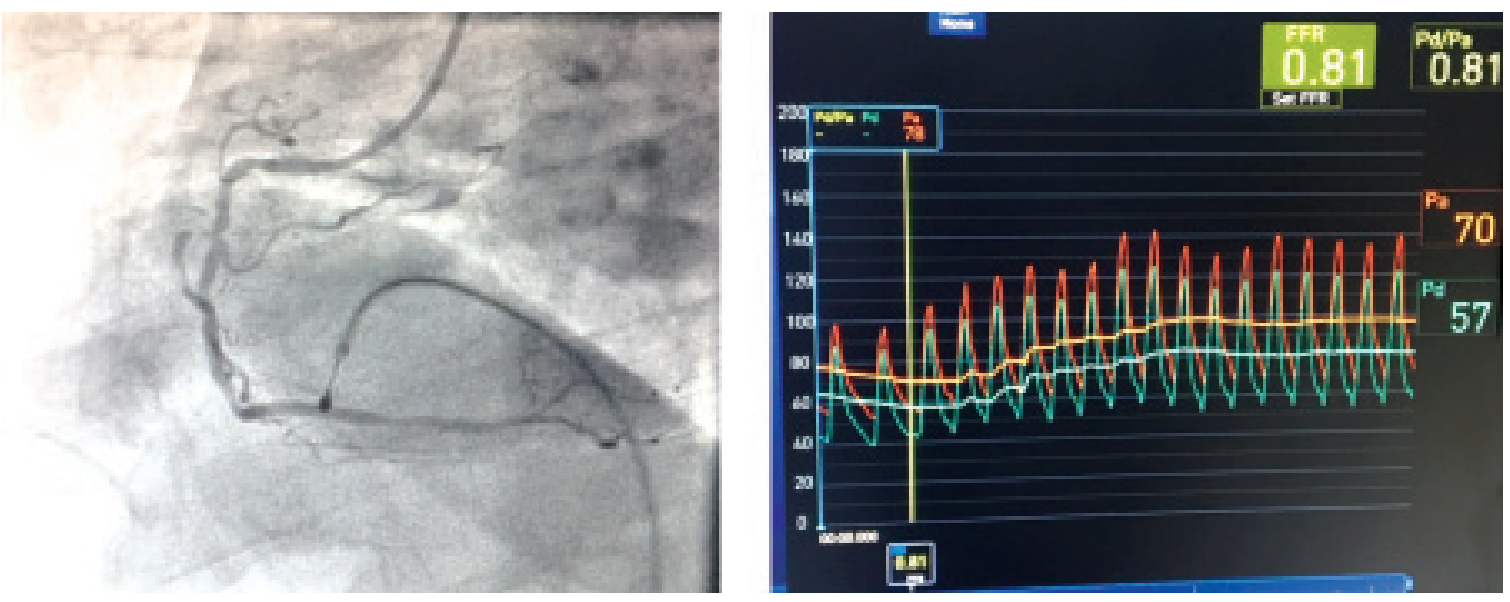

Fig.-7: Coronary Angiogram and FFR in a patient with angiographically significant Proximal LAD lesion on left panel and physiological study by FFR of 0.81 and kept on medical management
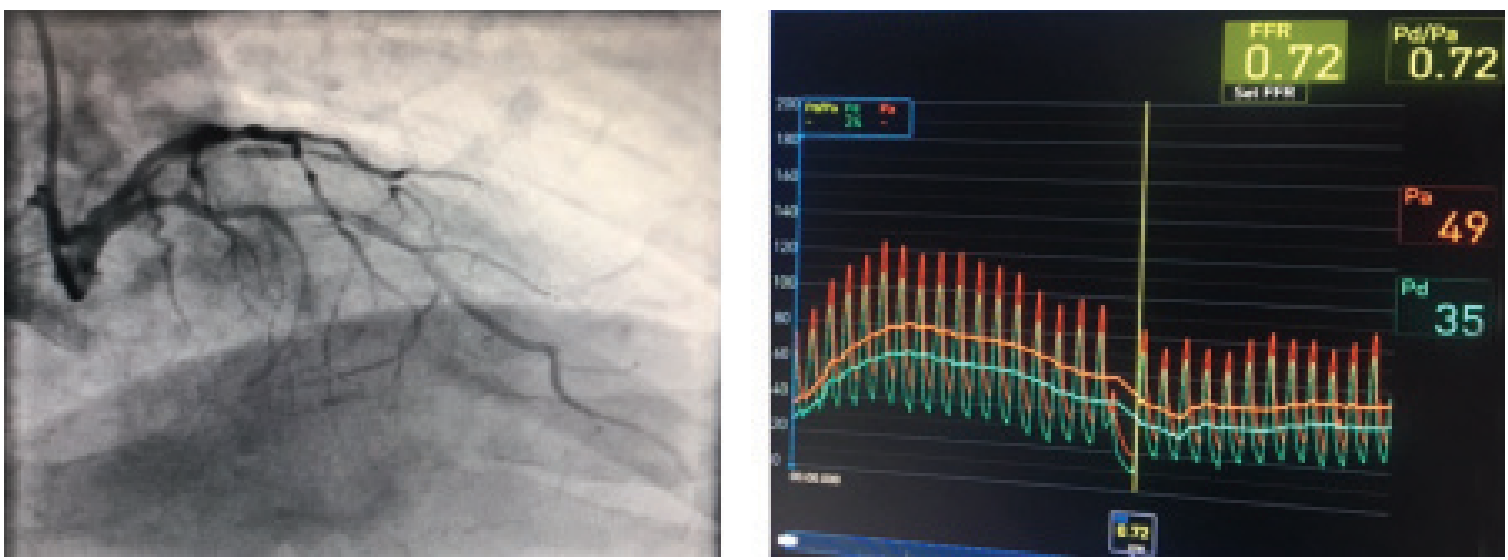

Fig.-8: Coronary Angiogram and FFR in a patient with angiographically significant Proximal LAD lesion on left panel and physiological study by FFR of $<0.72$ 


\section{Discussion:}

The presence of myocardial ischemia is a major prognostic factor in patients with symptomatic coronary artery disease and the decision to perform revascularization should be guided on the presence of myocardial ischemia. ${ }^{1}$ Fractional flow reserve (FFR) is a reliable physiological parameter to determine the functional significance of coronary stenosis. FFR guided $\mathrm{PCl}$ reported to be safe and effective in patients with various lesions subset. ${ }^{8}$ In addition, to coronary angiographic abnormalities, the presence and extent of inducible myocardial ischemia is an important prognostic factor in coronary artery disease. ${ }^{10}$ The absence of inducible myocardial ischemia is associated with excellent outcome during medical treatment. Therefore, revascularization of non-ischemic stenosis is usually not indicated. However, ischemia-inducing stenosis improves symptoms and outcomes.

The benefit of $\mathrm{PCl}$ as an initial treatment strategy in patients with stable CAD remains controversial. ${ }^{11} \mathrm{De}$ Bruyne et al has shown that that FFR guided PCl plus best available medical therapy reduces urgent revascularization. The potential results from revascularization depends on the extent and degree of myocardial ischemia. ${ }^{12}$

In the Bangladeshi interventional era, $\mathrm{PCl}$ is a common mode of treatment to open angiographically significant coronary artery stenosis. Although, Pre-PCI FFR is deem necessitate or mandated to assess physiological significance and thus, to the benefit of $\mathrm{PCl}$ by stenting. We are lacking of doing routine FFR due to poor socioeconomic status in Government or public hospitals. Recently, we performed some the FFR on those patient who were convinced to have it done before $\mathrm{PCl}$ and thus to avoid inappropriate stenting and its hazards.

Fractional flow reserve is generally known as an index to assess the physiological significances of coronary stenosis. A fractional flow reserve value of 0.80 or less (i.e. a drop in maximal blood flow of $20 \%$ or more caused by stenosis) as measured by coronary pressure wire during catheterization, indicating the potential of a stenosis to induce myocardial ischemia with an accuracy of more than $90 \%{ }^{13}$

In the current, non-randomized prospective observational study of 22 patients (male 20 and Female 2) in whom the coronary stenosis was angiographically significant, were enrolled for Pre-PCI FFR. FFR less than $<0.75$ were considered significant and $>0.75$ were non-significant. Thus, $\mathrm{PCl}$ were performed only on $\mathrm{FFR}<0.75$ and for FFR $>0.75$, were kept on medical management. We found that $59 \%(13)$ patient had non-significant FFR and thus, defer $\mathrm{PCl}$, while $41 \%$ (9) had significant FFR and $\mathrm{PCl}$ done by stenting with a Drug Eluting Stent(DES). The total number of patients are quite small in this present study. The total percentage distribution of non-significant FFR, is more among this studied group of patients, who has eye ball estimated coronary lesion about approximately $>70 \%-80 \%$. FFR was done to validate or justify the needs of $\mathrm{PCl}$, thus to reduce ischemic symptoms. Therefore, it is very primitive to conclude the exact scenario in our Bangladeshi patient population. That's why we recommend more patient inclusion and if possible to include multicenter in Bangladesh.

Many studies ${ }^{5,14}$ have proved that deferring $\mathrm{PCl}$ is safe, based on FFR in coronary intermediate stenosis and FFR guided $\mathrm{PCl}$ compared with CAG-guided $\mathrm{PCl}$ get much benefit to CAD patients.

Several author has favored FFR guided revascularization, as compared to angiography alone guided revascularization. ${ }^{5,15-16}$ De Bruyne et al demonstrated that patient with stable $C A D, F F R$ guided $P C l$ as compared with medical therapy alone improved the outcome. ${ }^{12}$

In the FFR versus angiography for Multivessel evaluation (FAME) trial, ${ }^{2}$ the rate of death, myocardial infarction and urgent repeat revascularization at 2 years with contemporary DES was less than half the rate among patients who received medical therapy alone. It is well known, that the benefits of $\mathrm{PCl}$ are mainly attributable to reduction of myocardial ischemia. ${ }^{17-18}$ Therefore, clinical practice guidelines currently recommended $\mathrm{PCl}$ only when symptoms of myocardial ischemia are identified. ${ }^{19}$

These important studies increased physician's awareness on the benefits of FFR-guided PCl and in the current guidelines on coronary revascularization of the ESC, FFR has been upgraded to a class $1 \mathrm{~A}$ classification in Multivessel $\mathrm{PCl} .{ }^{9}$

Moreover, the FAME II trial, subsequently reported that combination of an FFR-guided treatments strategy and the best available medical therapy, improved outcomes in patients with stable coronary disease compared to best available medical therapy. De Bruyne et al ${ }^{20}$ demonstrated that more than $25 \%$ of patients with stable coronary artery disease who were scheduled to undergo $\mathrm{PCl}$ on the basis of clinical and angiographic data, had no significant stenosis with an FFR value of 0.80 or less and were thus unlikely to have had ischemia. Also demonstrated that this patient had favorable clinical outcome at 2year medical therapy alone, a finding that is similar to results in patients with at least one clinically 
significant stenosis who were treated with $\mathrm{PCl}$ plus medical therapy.

FFR assess the significance of a coronary artery lesion during maximal vasodilation through the use of vasodilators such as adenosine. FFR value $(<0.75$ have high sensitivity $88 \%$ and specificity $100 \%$, positive predictive value $100 \%$ with an overall accuracy of $93 \%$. For detecting a reduction in coronary blood flow in patients with stable coronary artery disease. In ACS patients, FFR is limited, not reliable in STEMI patients, whom microvascular dysfunction as embolization of plaque occurs distally as well as inflammation and vasoconstriction. ${ }^{21}$ In NSTEMI there is less microvascular dysfunction and FFR may not be significant i.e., $<0.80$. This is because the clot may dissolve with the initiation of medical therapy resulting lesion to be less of a pressure gradient. Although FFR $<0.75$ has been shown to be significant in patient with stable coronary disease, this value may not be appropriate in patients with NSTEMI due to physiological differences.

Besides a very high sensitivity and specificity for the detection of inducible myocardial ischemia related to a coronary artery stenosis, FFR has some additional advantages and specific features that make it an easy and convenient practical index to be used in catheterization laboratory, particularly for the assessment of Multivessel disease.

Although, our present patient population number was very small and we found 59\% patient angiographically significant stenotic lesions has non-significant FFR and thus defer $\mathrm{PCl}$. Hence, it is very early to say, whether this number reflects the reality in our population in-terms of appropriateness of stenting. Also, we need to study FFR in more patients with ACS, stable coronary diseases and Multivessel disease.

In addition, FAME study showed that the FFR-guided PCI resulted in significant cost-saving by reducing stent use, re-hospitalizations and MACE. Thus, the FFR guided treatment could have been more economical in daily practice if decision making for $\mathrm{PCl}$ relies more strictly on FFR value. ${ }^{22}$

Baptista et al ${ }^{23}$ demonstrated that routine assessment of coronary lesions by FFR, safely changes patient management strategy in half of the patients with a low likelihood of events in deferred revascularization. In addition, our present study is very much consistent with Baptista et al, where we deferred $\mathrm{PCl}$ in more than 50\% of patient based on FFR value $<0.75$ and waiting to observe an events in future if any.

\section{Conclusion:}

Fractional flow reserve measurements were first introduced at the Mayo clinic in 1999, now is considered as the gold standard for the detection of myocardial ischemia. The safety of functional evaluation is attributed to identification of ischemia-causing coronary stenosis, and its contribution to judicious decision making revascularization. ${ }^{9,18}$ Although, some of the patient with FFR 0.75-0.76 had PCl based on his clinical significant angina. FAME study showed that FFR guided $\mathrm{PCI}$ resulted in significant cost saving by reducing stent use of inappropriate stenting, avoidance hospitalization and MACE. $^{22}$

Our present study, supported the rationale for the use of FFR in routine practice. In this present non-randomized observational study, we were able to justify that approximately $>70 \%-80 \%$ angiographically significant coronary stenosis by eye ball estimation, were not significant by $\mathrm{FFR}$ for $\mathrm{PCl}$ and thus, to prevent inappropriate stenting,

\section{Limitation:}

We already documented in our center, that FFR is an important tool to evaluate the clinical significance of ischemia, especially in a patient with angiographically significant stenosis. Thus, proved that not all coronary stenosis needs to be stented unless it is proved by FFR. Major limitation is the cost of FFR, if it is significant that is $<0.75$, then stenting of the coronary artery is mandated and it will increase the total cost of $\mathrm{PCl}$. On the contrary, if not significant, then it will help patient of not to have inappropriate stenting, repeat hospitalization due to stent induced ischemia.

\section{Future perspective}

FFR is a cost effective tool to determine the hemodynamic significance of coronary lesion, and can be used to guide appropriate $\mathrm{PCl}$ in the cost-conscious setting. Based on our observation, we recommend to make a national data base with mandatory FFR prior to any PCl except STEMI or NSTEMI and compare the benefits of FFR with multicenter involvement.

\section{References:}

1. Beller GA, Zaret BL: Contributions of nuclear cardiology to diagnose and prognosis of patients with coronary artery dfisease. Circulation 2000; 101:1465-1478

2. Boden WE, O'Rourke RA, Teo KK et al. Optimal medical therapy with or without $\mathrm{PCl}$ for stable coronary disease. N Eng J Med 2007; 356:15031516 
3. Shaw LJ, Beran DS, Maron DJ et al. Optimal medical therapy with or without percutaneous coronary intervention to reduce ischemic burden: Courage trial nuclear sub-study. Circulation 2008:117:128391

4. Pijls NH, De Bruyne B, Peels $\mathrm{K}$ et al. Measurement of fractional flow reserve to assess the functional severity of coronary artery stenosis. N Eng J Med 1996; 334:1703-1708

5. Tonino PA, De Bruyne B, Pijls NH et al. Fractional flow reserve versus angiography for guiding percutaneous coronary intervention. $\mathrm{N}$ Eng. J Med 2009; 360:213-224

6. Hamilos M, Muller $\mathrm{O}$, Cuisset $\mathrm{T}$ et al. Long term clinical outcome after fractional flow reserve-guided treatment in patients with angiographically equivocal left main coronary artery stenosias > Circulation 2009:120:1505-1512

7. Bech Gj, De Bruyne J, Koolen JJ et al. Fractional flow reserve to assess the functional severity of coronary artery stenosis. N engl J Med 1996; 334:1703-1708

8. De Bruyne B, Pijls NHJ, Bartunek J et,al. Fractional flow reserve in patients with prior myocardial infarction. Circulation 2001; 104:157-162

9. Wijns W, Kolh P, Danchin N et al. Guidelines on myocardial revascularization. Eur Heart J 2010; 31:2501-2555

10. Mancini GB, Hartigan PM, Shaw LJ et al. Predicting outcome in the COURAGE trial (Clinical Outcomes Utilizing Revascularization and Aggressive Drug Evaluation): Coronary anatomy versus ischemia. JACC Cardiovasc Interv 2014; 7: 195-201

11. Ziada K, Moliterno DJ. Revascularization for patients with stable coronary artery disease. BMJ 2014;348: g4099

12. De Bruyne B, Pijls NHJ, Kalesan B et al. Fractional flow reserve guided $\mathrm{PCl}$ versus medical therapy in stable coronay disease. N Eng J Med 2012; 367:991-1001

13. Pijls NHJ, van son JA, Kirkeeide RL et al. Experimental basis of determining maximum coronary myocardial and collateral blood flow by pressure measurements for assessing the severity before and after coronary angiography, Circulation 1993;86:1354-67

14. Pijls NH, van Schaardenburgh P, Manoharan $\mathrm{G}$ wet al. percutaneous coronary intervention of functionally non-significant stenosis: 5-year follow- up of the DEFER study. J Am Coll Cardiol 2007; 49:2105-2111

15. Muller $\mathrm{O}$, Mangiacapra F, Ntaliants A et al. Long term follow up after fractional flow reserve-guided treatment strategy in patients with an isolated proximal left anterior descending coronary artery stenosis. JACCV Cardiovasc Interv 2011; 4:1175-82

16. Li J, Elrashidi MY, Flammer Aj et al. Long-term outcomes of fractional flow reserve-guided vs angiography-guided $\mathrm{PCl}$ in contemporary practice. Eur Heart J 2013; 34:1375-83

17. Davis RF, Goldberg AD, Forman. Et al. Asymptomatic cardiac ischemia pilot study two year follow up: outcomes of patients randomized to initial strategies of medical therapy versus revascularization. Circulation 1997:95:2037-2043

18. Pijls NH, Fearon WF, Tonino PA et al. Fractional flow reserve versus angiography for guiding percutaneous coronary intervent in patients with Multivessel coronary artery disease: 2-year followup of the FAME (Fractional Flow Reserve versus Angiography for Multivessel evaluation) study. J Am Coll cardiol. 2010; 56:177-184

19. Levine GN, Bates ER, Blankenship JC et al. 2011 ACCF/AHA.SCAI Guideline for percutaneous coronary intervention: A report of the American College of Cardiology /American Heart Association Task Force on Practice guidelines. J Am Coll Cardiol 2011;58: e44-e122

20. De Bruyne B, Fearon WF, Pijls NH et al. Fractional flow Reserve-Guided PCl for stable coronary artery disease. N Eng J Med 2014; 371:1208-12017

21. Kern MJ, Samady $\mathrm{H}$ et al. Current concepts of integrated coronary physiology in the catheterization laboratory. JACC 2010; 55: 173-185

22. Fearon WF, Bornschein B, Tonino PA et al. Fractional flow reserve versus angiography for Multivessel evaluation (FAME) study investigators. Economic evaluation of fractional flow reserve-guided percutaneous coronary interventions in patients with Multivessel disease. Circulatin ; 2010;122:2545-2550

23. Baptista SB, Raposo L, Santos L et al. Impact of routine Fractional Flow reserve evaluation during coronary angiography on management strategy and clinical outcome. Cir Cardiovasc. Interv. 2016;9:e003288 